\title{
Double Incomplete Pyloromyotomy (A. Ezzat Technique): A New Technique for Infantile Hypertrophic Pyloric Stenosis: Preliminary Study
}

\author{
Ahmed Ezzat Rozeik ${ }^{*}$, Radi Elsherbini' ${ }^{2}$, Hamdi Almaramhy ${ }^{3}$ \\ ${ }^{1}$ Pediatric Surgery Unit, Zagazig University, Al Sharqia Governorate, Egypt \\ ${ }^{2}$ Pediatric Surgery Unit, Mansoura University, Mansoura, Egypt \\ ${ }^{3}$ Faculty of Medicine, Taibah University, Medina, KSA \\ Email: Ahmedezzat147@yahoo.com
}

Received 28 August 2014; revised 25 September 2014; accepted 20 October 2014

Copyright @ 2014 by authors and Scientific Research Publishing Inc.

This work is licensed under the Creative Commons Attribution International License (CC BY). http://creativecommons.org/licenses/by/4.0/

(c) (i) Open Access

\begin{abstract}
Background-Purpose: The study aimed to see the outcome of Double Incomplete Pyloromyotomy as new technique for surgical management of infantile hypertrophic pyloric stenosis (IHPS). Methods: This study was conducted in pediatric surgery unite, Zagazig University Hospital, Egypt. Fifteen patients were included in this study (11 male and 4 female) with IHPS from January 2012 to January 2013. Under general anesthesia, two longitudinal separated incisions at different planes as pyloromyotomy. Results: Postoperative vomiting and weight gain were recorded. Follow up period was 3 months. Vomiting improved within first 48 hours then stopped after that. Weight gain significantly increased after the operation when compared preoperatively. Conclusion: Double Incomplete Pyloromyotomy is a new, safe and effective procedure for treatment of infantile hypertrophic pyloric stenosis.
\end{abstract}

\section{Keywords}

Hypertrophic Pyloric Stenosis, Double Incomplete Pyloromyotomy

\section{Introduction}

Infantile hypertrophic pyloric stenosis (IHPS) continues to be a common pediatric surgical condition, with an

"Corresponding author.

How to cite this paper: Rozeik, A.E., Elsherbini, R. and Almaramhy, H. (2014) Double Incomplete Pyloromyotomy (A. Ezzat Technique): A New Technique for Infantile Hypertrophic Pyloric Stenosis: Preliminary Study. Open Journal of Pediatrics, 4, 253-256. http://dx.doi.org/10.4236/ojped.2014.44034 
incidence reported of 1 to 8 per 1000 live births [1] [2]. Projectile non bilious vomiting and its complications are common presentations [3] [4]. Diagnosis mainly depends on abdominal ultrsonography [5] [6].

Ramstedt's pyloromyotomy remains the standard surgical treatment with an excellent outcome [7]-[10]. An alternative technique like a double-Y pyloromyotomy offers good results for management of this condition [11].

The aim of the present study was to see the outcome of surgical management of IHPS by Double Incomplete Pyloromyotomy.

\section{Patients and Methods}

A prospective study was planned between January 2102 and January 2103; fifteen patients were included in this study with diagnosis of IHPS by abdominal ultrasonography. These patients were managed by DIP technique. Patients with gross congenital anomalies were excluded from this study. All patients were fully prepared preoperatively regarding hydration and acid base and electrolytes balance.

\section{Technique}

Under general anesthesia, right upper quadrant incision was done. Delivery of pyloric mass into the wound. Two longitudinal incisions was performed: one incision started in one side of the mass from its upper end till middle of it, another incision started in other side of the mass from its lower end till the middle of it as Figure 1 separation of pyloric muscle in both incisions till mucosa appear. After adequate hemostasis and checking of intact mucosa; abdominal closure in layers was done (A. Ezzat technique).

Oral feeding started 6 - 8 hours after surgery by dextrose water proceeding to half-strength milk then full feeds within the first $24 \mathrm{~h}$ postoperatively. Information on patient's demographics, postoperative vomiting and weight gain were collected. Patients were followed up for a period of 3 months.

\section{Results}

In this study of 15 patients; 11 were male while 4 were female. Mean age at presentation was 22 days (ranged from 16 days to 32 days). Projactile non bilious vomiting and acid-base disturbance were the main presentation in addition to weight loss and constipation. No mucosal perforation during operation or manifestations suggested it postoperatively. Vomiting improved then stopped within first $24-72 \mathrm{~h}$ after operation in all patients. We noted that weight gain observed in all patients from first week and proceeded till the end of follow up period. Mean preoperative weight was 2750 gms and the mean postoperative (after 3 months) was 5550 gms. No recurrence of vomiting or long-term complications and No need of re-do pyloromyotomy.

\section{Discussion}

Surgical management of infantile hypertrophic pyloric stenosis was described by Ramstedt in 1912. Till now it is the most popular procedure for IHPS [7]-[10]. Some modifications as Double-Y pyloromyotomy depending on the same principle with nearly the same outcome [11]. These procedures split the pyloric muscle completely in the same plane. Long-term follow of the patients specially after Ramstdt's procedure showed some unfavorable complications as rapid gastric emptying and increased duodenal reflux which explain increased incidence
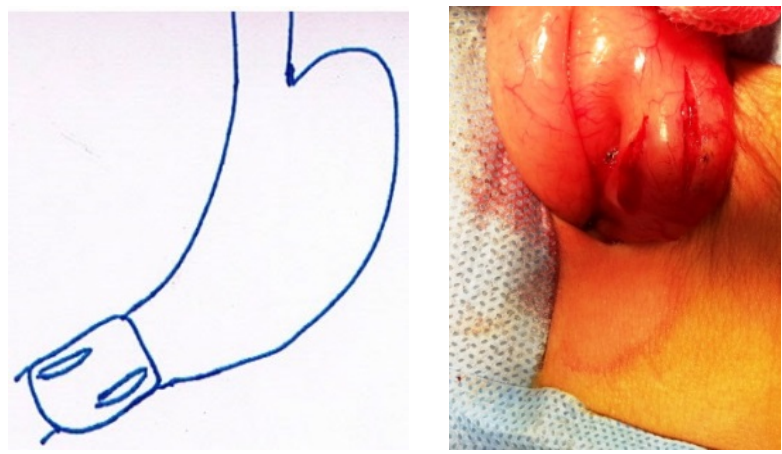

Figure 1. Incisions of Double Incomplete Pyloromyotomy. 
of peptic ulcer in several series [12] [13]. Lasheen et al. [14] reported segmental internal sphincterotomy for treatment of chronic anal fissure by doing two incomplete incisions in different planes to decrease the incidence of fecal incontinence.

Depending on the same idea we applied double incomplete pyloromyotomy for surgical treatment of IHPS by doing two incomplete incisions in different planes of the pylorus. This new procedure has nearly the same outcome of Ramstedt's procedure with stopping of vomiting and significant weight gain along the follow up period. We suggest that the new technique decrease the incidence of rapid gastric emptying and duodenal reflux after Ramsted's procedure because of our technique did-not split the pyloric muscle in the same plane. In Ramstedt's procedure, the pyloric mucosa bulges after pyloromyotomy, leading to formation of a gutter inside the pylorus with stasis of food and susceptibility of gastritis and ulcer. In our technique the mucosa did-not bulge due to incomplete incisions and subsequently decreased the incidence of the complications.

Double Incomplete Pyloromyotomy offers the same results of Ramstedt's procedure regarding stopping vomiting, weight gain and low incidence of complications. This new technique needs longer follow up with studying of gastric emptying and pyloric sphincter function.

\section{Conclusion}

Double Incomplete Pyloromyotomy is a new, safe and effective technique for treatment Infantile Hypertrophic Pyloric Stenosis. It has the same results of stander Ramstedt's procedure but needs longer follow up and further studies.

\section{References}

[1] Panteli, C. (2009) New Insights into Pathogenesis of Infantile Pyloric Stenosis. Pediatric Surgery International, 25, 1043-1052. http://dx.doi.org/10.1007/s00383-009-2484-x

[2] Gotly, L., Bland, A., Kimble, R., et al. (2009) Pyloric Stenosis: A Retrospective Study of an Australian Population. Emergency Medicine Australasia, 21, 407-413.

[3] Chan, S.M., Chan, E.R., Chu, W.C., Cheung, S.T., Tam, Y.H. and Lee, K.H. (2011) Hypertrophic Pyloric Stenosis in a New Born: A Diagnostic Dilemma. Hong Kong Medical Journal, 17, 245-247.

[4] Mahalik, S., Prasad, A., Sinha, A. and Kulshrestha, R. (2010) Delayed Presentation of Hypertrophic Pyloric Stenosis: A Rare Case. Journal of Pediatric Surgery, 45, 9-11. http://dx.doi.org/10.1016/j.jpedsurg.2009.11.012

[5] Huang, Y.L., Lee, H.C., Yeung, C.Y., Chen, W.T., Jiang, C.B., Shew, J.C. and Wang, N.L. (2009) Sonogram before and after Pyloromyotomy: The Pyloric Ratio in Infantile Hypertrophic Stenosis. Pediatrics \& Neonatology, 50, 117120. http://dx.doi.org/10.1016/S1875-9572(09)60046-2

[6] Muramori, K., Nagasaki, Y. and Kawanami, T. (2002) Ultrasonographic Serial Measurement of Morphologic Resolution of the Pylorus after Ramstedt's Pyloromyotomy for Infantile Hypertrophic Pyloric Stenosis. Journal of Ultrasound in Medicine, 26, 1681-1687.

[7] Aspelund, G. and Langer, J.C. (2007) Current Management of Hypertrophic Pyloric Stenosis. Seminars in Pediatric Surgery, 16, 27-33. http://dx.doi.org/10.1053/j.sempedsurg.2006.10.004

[8] Karen, W., Robert, H., Andrew, J.A., Caroline, K. and Nadia, B. (2010) Early Development Outcome of Infants with Infantile Hypertrophic Pyloric Stenosis. Journal of Pediatric Surgery, 45, 2369-2372. http://dx.doi.org/10.1053/j.sempedsurg.2006.10.004

[9] Esmaeel, T., John, B., Sherif, E., Sebastien, D., Pramod, P., Helen, F. and Jean, M. (2007) Evaluation of Surgical Approaches to Pyloromyotomy: A Single-Center Experience. Journal of Pediatric Surgery, 42, 865-868. http://dx.doi.org/10.1053/j.sempedsurg.2006.10.004

[10] Yagmurlu, A., Chalmer, J., Yoyngson, G., et al. (2004) Comparison of the Incidence of Complications in Open and Laparoscopic Pyloromyotomy: A Concurrent Single Institution Series. Journal of Pediatric Surgery, 39, 292-296. http://dx.doi.org/10.1016/i.jpedsurg.2003.11.047

[11] Alalayet, Y.F., Miserez, M., Mansoor, K. and Khan, A.M. (2009) Double-Y Pyloromyotomy: A New Technique for Surgical Management of Infantile Hypertrophic Pyloric Stenosis. European Journal of Pediatrics, 19, 17-20. http://dx.doi.org/10.1055/s-2008-1039025

[12] Tam, P.K., Saing, H., Koo, J., et al. (1985) Pyloric Function Five to Eleven Years after Ramstedt’s Pyloromyotomy. Journal of Pediatric Surgery, 20, 236-239.

[13] Sun, W.M., Doran, S.M., Jones, K.L., Davidson, G., Dent, J. and Horowitz, M. (2000) Long-Term Effect of Pyloro- 
myotomy on Motility and Gastric Emptying. The American Journal of Gastroenterology, 95, 92-100. http://dx.doi.org/10.1111/j.1572-0241.2000.01705.x

[14] Lasheen, A.E., Morsy, M.M. and Fiad, A.A. (2011) Segmental Internal Sphincterotomy: A New Technique for Treatment of Chronic Anal Fissure. Journal of Gastrointestinal Surgery, 15, 2271-2274.

http://dx.doi.org/10.1007/s11605-011-1689-1 
Scientific Research Publishing (SCIRP) is one of the largest Open Access journal publishers. It is currently publishing more than 200 open access, online, peer-reviewed journals covering a wide range of academic disciplines. SCIRP serves the worldwide academic communities and contributes to the progress and application of science with its publication.

Other selected journals from SCIRP are listed as below. Submit your manuscript to us via either submit@scirp.org or Online Submission Portal.
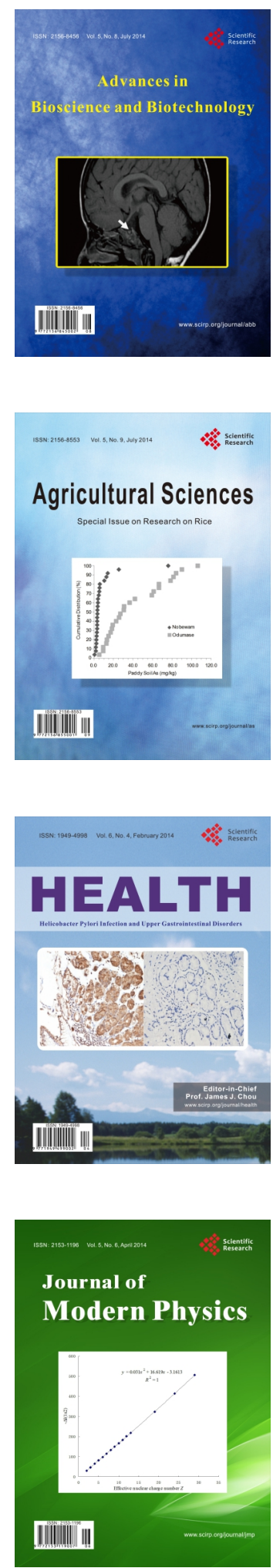
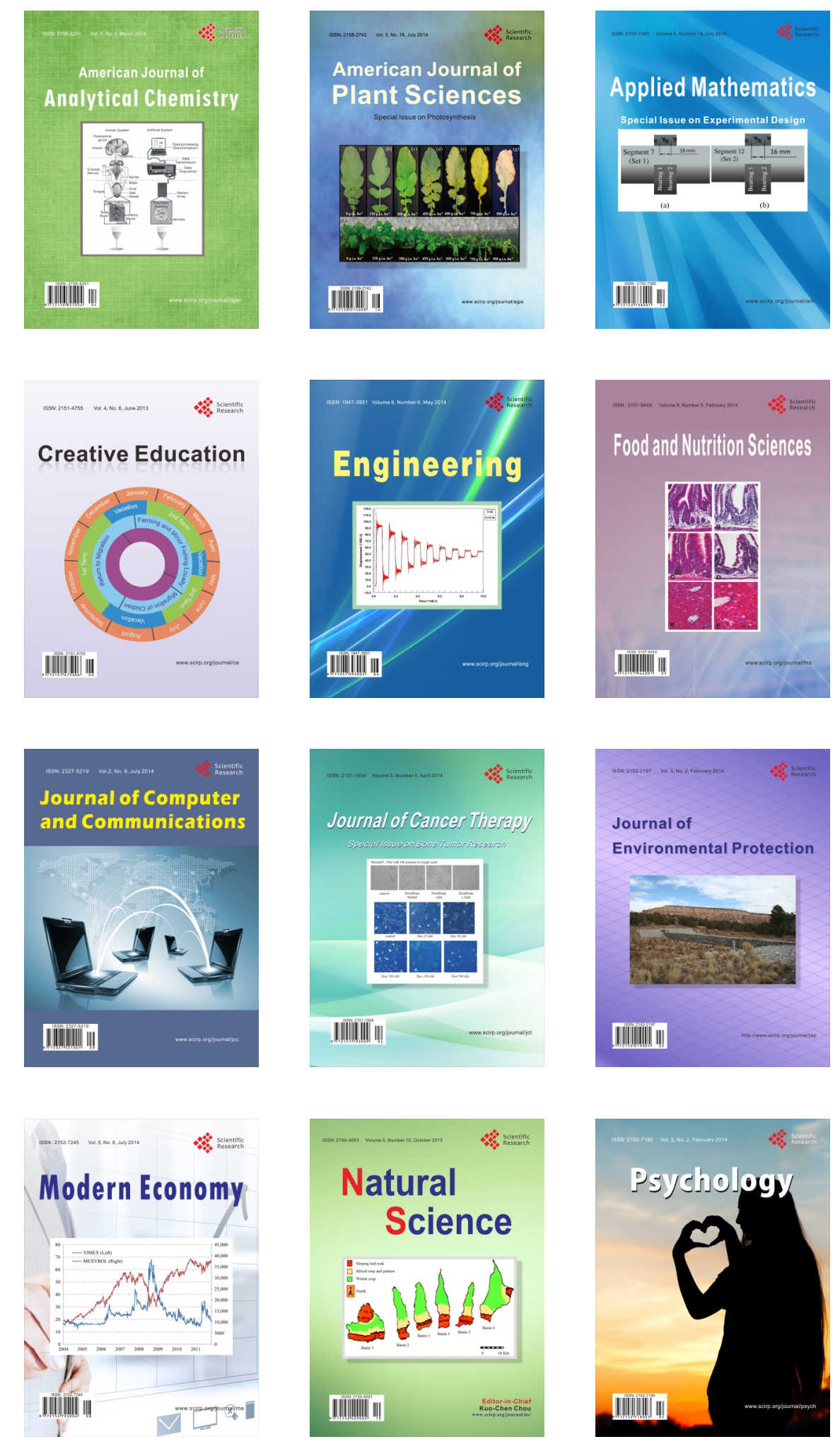